\title{
Evaluation of Microbial Adhesion and Biofilm Formation on Nano-Structured and Nano-Coated Ortho-Prosthetic Materials by a Dynamic Model
}

\author{
Simone Leonetti ${ }^{1}$ (D) Benedetta Tuvo ${ }^{1}$, Beatrice Campanella ${ }^{2}$, Stefano Legnaioli ${ }^{2}$, \\ Massimo Onor ${ }^{2}{ }^{\mathbb{D}}$, Emilia Bramanti ${ }^{2}$, Michele Totaro ${ }^{1}$, Angelo Baggiani ${ }^{1}$, Serena Giorgi ${ }^{1}$, \\ Gaetano Pierpaolo Privitera ${ }^{1}$, Nicola Piolanti ${ }^{3}$, Paolo Domenico Parchi ${ }^{1,3}$ and \\ Beatrice Casini ${ }^{1, *(\mathbb{D})}$ \\ 1 Department of Translational Research, N.T.M.S., University of Pisa, via San Zeno, 37/39-56127 Pisa, Italy; \\ s.leonetti@live.com (S.L.); tuvobenedetta@hotmail.it (B.T.); michele.totaro.unipi@hotmail.com (M.T.); \\ angelo.baggiani@med.unipi.it (A.B.); giorgiserena@yahoo.it (S.G.); gaetano.privitera@med.unipi.it (G.P.P.); \\ paolo.parchi@unipi.it (P.D.P.) \\ 2 Institute of Chemistry of Organometallic Compounds, National Research Council, via Giuseppe Moruzzi, \\ 1-56124 Pisa, Italy; beatrice.campanella@pi.iccom.cnr.it (B.C.); s.legnaioli@pi.iccom.cnr.it (S.L.); \\ massimo.onor@pi.iccom.cnr.it (M.O.); emilia.bramanti@pi.iccom.cnr.it (E.B.) \\ 3 Orthopaedic and Traumatology Division, Azienda ospedaliera-Universitaria Pisana, via Roma, \\ 67-56126 Pisa, Italy; nicpio@hotmail.it \\ * Correspondence: beatrice.casini@med.unipi.it; Tel.: +39-050-221-3590
}

Received: 20 January 2020; Accepted: 4 February 2020; Published: 5 February 2020

\begin{abstract}
The bio-engineering technologies of medical devices through nano-structuring and coating was recently proposed to improve biocompatibility and to reduce microbial adhesion in the prevention of implantable device-related infections. Our aim was to evaluate the ability of new nano-structured and coated materials to prevent the adhesion and biofilm formation, according to the American Standard Test Method ASTM-E2647-13. The materials composition was determined by X-ray Fluorescence and Laser Induced Breakdown Spectroscopy. Silver release was evaluated by Inductively Coupled Plasma Mass Spectrometry analysis. The gene expression levels of the Quorum Sensing Las and $R h l$ system were evaluated by the $\Delta \Delta \mathrm{Ct}$ method. The Log bacterial density $\left(\log \mathrm{CFU} / \mathrm{cm}^{2}\right)$ on TiAl6V4 was $4.41 \pm 0.76$ and $4.63 \pm 1.01$ on TiAl6V4-AgNPs compared to $2.57 \pm 0.70$ on CoCr and $2.73 \pm 0.61$ on CoCr-AgNPs (P $<0.0001$, A.N.O.V.A.- one way test). The silver release was found to be equal to $17.8 \pm 0.2 \mu \mathrm{g} / \mathrm{L}$ after the batch phase and $1.3 \pm 0.1 \mu \mathrm{g} / \mathrm{L}$ during continuous flow. The $r h l R$ gene resulted in a 2.70-fold increased expression in biofilm growth on the silver nanoparticles (AgNPs) coating. In conclusion, $\mathrm{CoCr}$ showed a greater ability to reduce microbial adhesion, independently of the AgNPs coating. The silver release resulted in promoting the up-regulation of the Rhl system. Further investigation should be conducted to optimize the effectiveness of the coating.
\end{abstract}

Keywords: biofilm; Drip Flow Biofilm Reactor; implantable device-related infections; titanium and cobalt-chrome nano-structured materials; silver nanoparticles; Quorum Sensing

\section{Introduction}

Even if the total joint replacement is among the most successful surgical procedures in terms of consistent improvement of the patient's quality of life, it may be not free of complications, and infections are among the most challenging ones. Infections related to the implant of orthopedic devices are included within the description of surgical site infections (SSI), and they have great relevance for the significant clinical and financial impact on the patients, as well as for the treating surgeon and 
the healthcare system [1]. Despite the progress in diagnostics in recent years, the real percentage of peri-prothesis infection (PPI) is probably underestimated. Barberan J. et al. [2], reported that surgical site infections represent a potential complication in prosthetic orthopedic surgery, with an incidence between $0.5 \%$ and $3 \%$ for the first total hip replacement and total knee replacement implants, reaching up to $20 \%$ in case of revisions. Moreover, the PPI is the third cause of prosthetic implant failure in primary surgery and is the leading cause in revision surgery within the first five years [3]. More recently, these data have been confirmed by Kenney C. et al. in a systematic review of the causes of failure of revision total hip arthroplasty [4].

The bio-engineering technologies of medical devices through nano-structuring and coating has recently been proposed, not only to prevent microbial adhesion, but also to improve the biocompatibility of materials [5-8] to develop the ideal orthopedic implant.

Conversely, in the Second International Consensus Meeting on Prosthetic Joint Infection, it was stressed that the duration of long-term anti-infective effect of the modified implant surface is unknown, and that further studies are needed [9].

Titanium (Ti6Al4V) and cobalt chromium (CoCr) implants are widely used in the orthopedic field due to their mechanical and biological proprieties [10,11]. Among the nano-coating technologies, silver nanoparticles (AgNPs) are the most used for their bactericidal and cytotoxic activity on microorganisms [12,13], but their instability is often underestimated. The different values of $\mathrm{pH}$ and oxygen concentrations can cause AgNPs' dissociation or aggregation, reducing their stability and their adhesion on surfaces [14].

The efficacy of nano-structuring and coating materials should be evaluated through appropriate experimental models [15]. Static models are particularly useful and easy to set up for examining early events in bacterial biofilm formation and to identify signals that modulate the transition from a planktonic to a biofilm mode of growth. Because most of the cultures are neither continuously supplied with fresh medium nor are they aerated, there may be a limitation of nutrients, which may encourage an inability to easily generate mature biofilms. The static models generate a stable structure and limits the possibility of cell detachment, ensuring that observed differences in cell numbers are due to cell death rather than detachment [16]. The dynamic models in continuous flow enable the formation of mature biofilms with optimal conditions mimicking real conditions in vitro [16,17]. Among the advantages of continuous-flow models is the ability to compare the effects that different media, oxygen concentrations, temperature shifts, and substances exert on a biofilm at any developmental phase. These models also allow for evaluating the effects that transiently occurring molecules, such as antibiotics or adherence inhibitors, have on biofilms. However, the technical disadvantages of continuous-flow biofilms include increased experimental complexity as well as possible formation/trapping of air bubbles in the setup tubing [15].

The aim of this study is to evaluate the ability of new titanium and cobalt-chrome nanostructured materials, coated or not with AgNPs, to prevent and reduce the adhesion and microbial biofilm formation. This evaluation was conducted according to the standard ASTM-E2647-13, the standard test method for quantification of a Pseudomonas aeruginosa biofilm grown using a Drip Flow Biofilm Reactor with low shear and continuous flow. The release of AgNPs and its effect on the Quorum Sensing genes regulation were also determined.

\section{Methods}

\subsection{Coupon Materials}

Coupons with a surface of $18.75 \mathrm{~cm}^{2}(25 \times 75 \times 1 \mathrm{~mm})$ were made in nanostructured titanium (TiAl6V4) and cobalt-chrome, with or without AgNPs coating. A total of 32 coupons were tested (TiAl6V4 $\mathrm{n}=8$, TiAl6V4-Ag $\mathrm{n}=8, \mathrm{CoCr} \mathrm{n}=8, \mathrm{CoCr}-\mathrm{Ag} \mathrm{n}=8$ ). The number of AgNPs used for coating was unknown because this was covered by industrial property rights, though it was experimentally assessed determined by X-ray Fluorescence (XRF) and Laser Induced Breakdown Spectroscopy (LIBS). 


\subsection{The Drip Flow Biofilm Reactor (DFBR)}

For the cell adhesion capacity analysis, biofilms were grown on the coupons in four parallel flow chambers DFBR (four-chamber Drip Flow Biofilm Reactor ${ }^{\circledR}$, Biosurface Technologies Corporation, Bozeman, MT, USA). Each channel had an individual lid fixed with screws that kept the conditions aseptic during the sampling process. Each channel contained a coupon of $18.75 \mathrm{~cm}^{2}$. This bioreactor is recommended by the ASTM Standard Method E2647-13 [18] for growing, sampling and analyzing a Pseudomonas aeruginosa biofilm formed under low shear and continuous flow, trying to mimic the environmental conditions found in medical devices and the human body [16].

\subsection{Culture and Inoculum Preparation}

An isolated colony of Pseudomonas aeruginosa (ATCC 700888) from an R2A plate (VWR chemicals, Radnor, PA, USA) was aseptically removed and inoculated into $100 \mathrm{~mL}$ of sterile Tryptic Soy Broth $3 \mathrm{gr} / \mathrm{L}$ (TSB, Merck Millipore, Burlington, MA, USA) and the bacterial suspension was incubated in an environmental shaker at $35 \pm 2^{\circ} \mathrm{C}$ for 20 to $24 \mathrm{~h}$. The viable bacterial density was evaluated equal to $10^{8} \mathrm{CFU} / \mathrm{mL}$ by serial dilution and plating.

\subsection{DFBR Batch Phase}

After setting up the reactor as described in the user manual, each coupon was inserted into each reactor channel (4 channels), and $15 \mathrm{~mL}$ of sterile TSB $3 \mathrm{gr} / \mathrm{L}$ and $1 \mathrm{~mL}$ of bacterial inoculum were aseptically added in each channel. The reactor system was incubated at room temperature $\left(21 \pm 2^{\circ} \mathrm{C}\right)$ for $6 \mathrm{~h}$, in the level position.

\subsection{Continuous Flow Phase}

After the static phase, the influent nutrient tubing line was aseptically connected to the carboy containing the continuous flow nutrient broth (sterile TSB $270 \mathrm{mg} / \mathrm{L}$ ), each line was attached through a pump head and a sterile needle was connected at the end of each line. The continuous flow of nutrients was pumped into the reactor through a pump set at a flow rate equal to $200 \mathrm{~mL} / \mathrm{h}$ ( $50 \mathrm{~mL} / \mathrm{h}$ per channel). The reactor was operated in continuous flow mode for $48 \mathrm{~h}$.

\subsection{Biofilm Sampling and Population Density Determination}

After $48 \mathrm{~h}$, each coupon was aseptically removed from the channel and it was immersed in $45 \mathrm{~mL}$ of sterile buffered water $\left(0.0425 \mathrm{~g} / \mathrm{L} \mathrm{KH}{ }_{2} \mathrm{PO}_{4}\right.$ distilled water, filter sterilized and $0.405 \mathrm{~g} / \mathrm{L} \mathrm{MgCl} \cdot 6 \mathrm{H}_{2} \mathrm{O}$ distilled water, filter sterilized). The biofilm-covered coupon surface was scraped in a downward direction for approximately $15 \mathrm{~s}$, using the flat end of a sterile spatula. The scraping process was repeated 3 to 4 times, throughout the entire surface of the coupon. A total of $1 \mathrm{~mL}$ of sterile buffered water was pipetted over the top surface of the coupon for a total of 5 rinses. The final volume was $50 \mathrm{~mL}$.

The scraped biofilm samples were homogenized at 20,500 $\pm 5000 \mathrm{r} / \mathrm{min}$ for $30 \mathrm{~s}$. The homogenizer was decontaminated before next use with $70 \%$ ethanol for $15 \mathrm{~s}$ and rinsing with sterile buffered water for $30 \mathrm{~s}$. Total bacterial count was assessed for each sample by serial 10 -fold dilutions and plating each dilution in duplicate in R2A (VWR chemicals, Radnor, PA, USA), incubated for 17 to $20 \mathrm{~h}$ at $35 \pm 2{ }^{\circ} \mathrm{C}$. Biofilm population density was recorded as Log colony forming units on surface area.

\subsection{Statistical Analysis}

Analysis of Variance, ANOVA, One-way test and Holm-Sidak's multiple comparisons test were performed to observe statistical significance between coupons. The statistic elaboration was conducted by GraphPad Prism ${ }^{\circledR}$ version 8.0.1 (GraphPad Software Inc., San Diego, CA, USA). 


\subsection{Coupons Analysis and Silver Release}

Each type of coupon was tested by XRF and LIBS analyses.

X-ray Fluorescence was performed using the Elio ED-XRF portable spectrometer (XGLab, Italy). The X-ray tube had a Rh anode and the measurements area was about $1 \mathrm{~mm}^{2}$. The spectrometer resolution was $130 \mathrm{eV}$ at the $\mathrm{Mn} \mathrm{K} \alpha$ line. The acquisition time, energy of the $\mathrm{X}$-ray tube and current were set at $90 \mathrm{~s}, 40 \mathrm{keV}$ and $40 \mu \mathrm{A}$, respectively.

LIBS analyses were done using Modì (MARWAN TECHNOLOGY, Pisa, Italy), a mobile LIBS instrument equipped with a dual pulse laser (Nd-YAG, $\lambda=1064 \mathrm{~nm}$, single pulse energy up to $80 \mathrm{~mJ}$ in $100 \mathrm{~ns}$ ) and a non-intensified double grating spectrometer (AvaSpec Dual-Channel Fiber Optic Spectrometer from Avantes). The spectrometer simultaneously covered the spectral interval between 200 and $430 \mathrm{~nm}$ (with a resolution of $0.1 \mathrm{~nm}$ ) and between 415 and $900 \mathrm{~nm}$ (with resolution of $0.3 \mathrm{~nm}$ ).

Silver release was assessed in the culturing medium, during the batch phase (6 $\mathrm{h}$ later) and during the continuous flow after 18-30-42-54 h. A negative control, through the medium without coupons contact, was carried out at time zero from the beginning of the test.

An Agilent 7700x inductively coupled plasma mass spectrometer (ICP-MS) (Agilent Technologies, Santa Clara, CA, USA) equipped with a MicroMist nebulizer and a Peltier cooled $\left(2{ }^{\circ} \mathrm{C}\right)$ quartz Scott-type double pass spray chamber was used for the quantification of ${ }^{107} \mathrm{Ag}$ and ${ }^{109} \mathrm{Ag}$. A solution of $10 \mu \mathrm{g} / \mathrm{L}$ iridium in $2 \% \mathrm{HNO}_{3}$ was used as internal standard. The operating parameters for ICP-MS were optimized with a tuning solution containing $1.0 \mathrm{ng} / \mathrm{mL}$ of $\mathrm{Ce}, \mathrm{Co}, \mathrm{Li}, \mathrm{Mg}, \mathrm{Tl}$ and $\mathrm{Y}$ in $2 \% \mathrm{HNO}_{3}$. Silver quantitation was based on external calibration with standard solutions of $\mathrm{AgNO}_{3}$ (6 solutions in the $0.5-20 \mathrm{ng} / \mathrm{mL}$ range). Quality control was performed by analyzing a $5 \mathrm{ng} / \mathrm{mL} \mathrm{AgNO}_{3}$ standard after each sample. For the analysis, $2 \mathrm{~mL}$ of sampled TSB were treated with $2 \mathrm{~mL}$ of $69 \% \mathrm{HNO}_{3}$ and maintained at $90^{\circ} \mathrm{C}$ for $1 \mathrm{~h}$. Subsequently $2 \mathrm{~mL}$ of $30 \% \mathrm{H}_{2} \mathrm{O}_{2}$ were added and the sample placed again at $90^{\circ} \mathrm{C}$ for $1 \mathrm{~h}$. Before the analysis, the sample was diluted 1:10 in deionized water.

\subsection{Quorum Sensing Expression Analysis}

The effects of silver on the QS genes expression of P. aeruginosa growth on TiAl6V4-Ag coupons, were evaluated with mRNA extraction according to the RNeasy PowerBiofilm protocol (Qiagen, Germantown, MD, USA), determination of RNA concentration was through using a spectrophotometer, reverse transcription was according to the QuantiNova Reverse Transcription protocol (Qiagen, USA), and finally amplification of the target genes by realtime-PCR according to the QuantiNova SYBR Green PCR protocol (Qiagen, USA). The target genes were las $R$ and $r h l R$ whilst $r p o D$ was considered the housekeeping gene. The primers used for the PCR reaction were for lasR forward: $5^{\prime}$-AAGGAAGTGTTGCAGTGGTG-3', reverse: 5'-GAGCAGTTGCAGATAACCGA-3'; for $r h l R$ forward: 5'-GACCAGGAGTTCGACCAGTT-3', reverse: $5^{\prime}$-GGTAGGCGAAGACTTCCTTG-3'; for rpoD forward: 5'-CTGCAGGCCCTGGGCGAGAA-3', reverse: $5^{\prime}$-CTCGGGCGATCAACTCTTTC-3' [19].

The thermal cycling protocol, carried out using the Bio-Rad CFX Connect Real-Time PCR Detection System (Bio-Rad Laboratories, Berkeley, CA, USA), was: $95^{\circ} \mathrm{C}, 15 \mathrm{~min} ; 35$ cycles of $\left(95^{\circ} \mathrm{C}, 30 \mathrm{~s} ; 60^{\circ} \mathrm{C}\right.$, $30 \mathrm{~s} ; 72^{\circ} \mathrm{C}, 30 \mathrm{~s}$ ); final extension at $72^{\circ} \mathrm{C}$ for $10 \mathrm{~min}$ and $4{ }^{\circ} \mathrm{C}$ hold. Data analysis was carried out using the Bio-Rad CFX Manager 3.1 version 3.1.1.5.17.0823 program (Bio-Rad Laboratories, Berkeley, CA, USA) and the analysis of the relative expression was conducted using the Livak equation $\left(2^{-\Delta \Delta C T}\right)$ [20].

\section{Results}

\subsection{Population Density Determination}

The results of the population density determination, obtained by analyzing eight coupons by the type of material, showed a Log bacterial density $\left(\log C F U / \mathrm{cm}^{2}\right)$ equal to $4.41 \pm 0.76$ on TiAl6V 4 coupons and $4.63 \pm 1.01$ on TiAl6V4-AgNPs coupons. Lower values were found on $\mathrm{CoCr}$ coupons, respectively equal to $2.57 \pm 0.70$ on $\mathrm{CoCr}$ and $2.73 \pm 0.61$ on $\mathrm{CoCr}-\mathrm{AgNPs}$ (Figure 1). This difference was statistically significant. The P-value obtained by ANOVA one-way test was $<0.0001$, and results obtained by 
Holm-Sidak's multiple comparisons test were significant between titanium and chromium-cobalt $(<0.0001)$, but not significant between the same material coated and not coated $(>0.92)$.

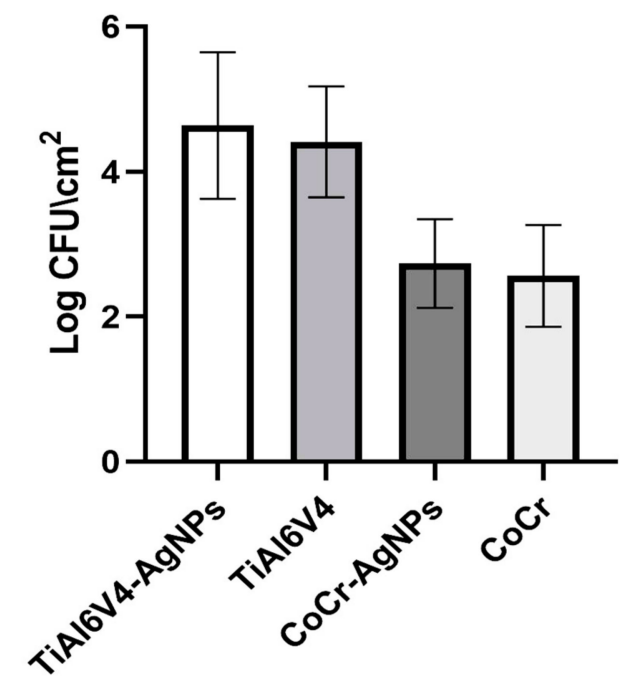

Figure 1. Log population density (means and standard deviations) for each material evaluated.

\subsection{Coupons Analysis and Silver Release}

The XRF results are reported in Figure 2.
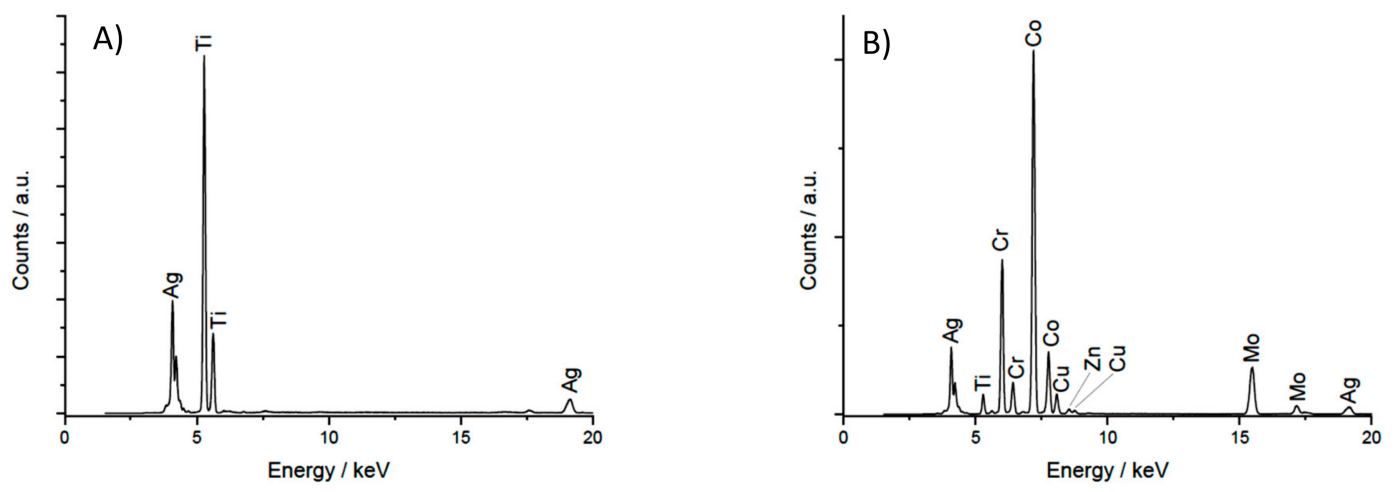

Figure 2. X-ray Fluorescence (XRF) spectra of TiAl6V4-AgNP (A) and CoCr-AgNP (B) coupons.

XRF spectra of TiAl6V4 coupons coated with AgNPs confirmed the presence of both Ti and Ag on the coupons' surface, while the spectra from CoCr-AgNPs showed copper as well as chrome, cobalt and silver.

Multiple acquisitions on the same point by LIBS allowed for collecting information from successive layers of the coupon, estimating 1-2 $\mu \mathrm{m}$ as the depth of the laser pulse [21].

In-depth LIBS measurements revealed that in both types of coupons silver was present, mostly in the first 1-2 $\mu \mathrm{m}$ layers. After 8 laser shots on the same point, the signal from Ag was no longer detectable. Titanium, conversely, was present homogeneously throughout the TiAl6V4-AgNPs coupons. On the surface of CoCr-AgNPs coupons, besides silver, titanium was also detectable, which may be a pollutant from the manufacturing process. Chromium, cobalt and copper were homogeneous throughout the coupons (Figure 3). 

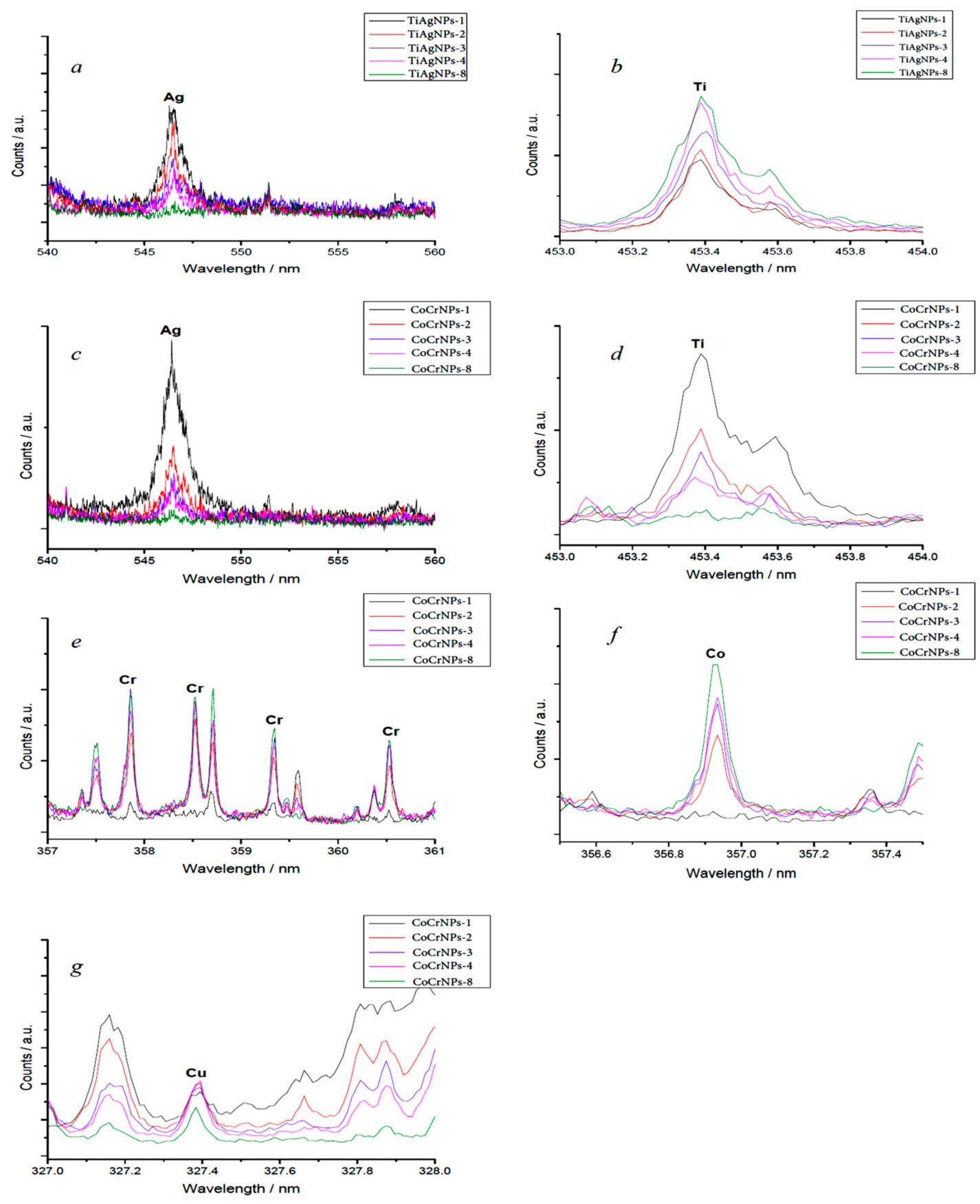

Figure 3. Insets of Laser Induced Breakdown Spectroscopy (LIBS) spectra relative to Ag (a) and $\mathrm{Ti}$ (b) in TiAl6V4-AgNPs coupons and $\mathrm{Ag}(\mathbf{c}), \mathrm{Ti}(\mathbf{d}), \mathrm{Cr}(\mathbf{e}), \mathrm{Co}(\mathbf{f}), \mathrm{Cu}(\mathbf{g})$ in CoCr-AgNPs coupons. Sample numbering indicates the progressive order by which the analysis was made by repeatedly shooting the laser on the same point.

The AgNPs' release in culturing medium was evaluated by ICP-MS analysis (Figure 4). The concentration of $\mathrm{Ag}$, corrected for dilutions, was equal to $17.8 \pm 0.2 \mu \mathrm{g} / \mathrm{L}$ during the batch phase. During the continuous flow, the concentration for each $12 \mathrm{~h}$ following the batch phase were $0.9 \pm 0.1 \mu \mathrm{g} / \mathrm{L} ; 0.8 \pm 0.1 \mu \mathrm{g} / \mathrm{L} ; 1.9 \pm 0.2 \mu \mathrm{g} / \mathrm{L}$ and $1.4 \pm 0.1 \mu \mathrm{g} / \mathrm{L}$ respectively. The negative control was free from AgNPs. 


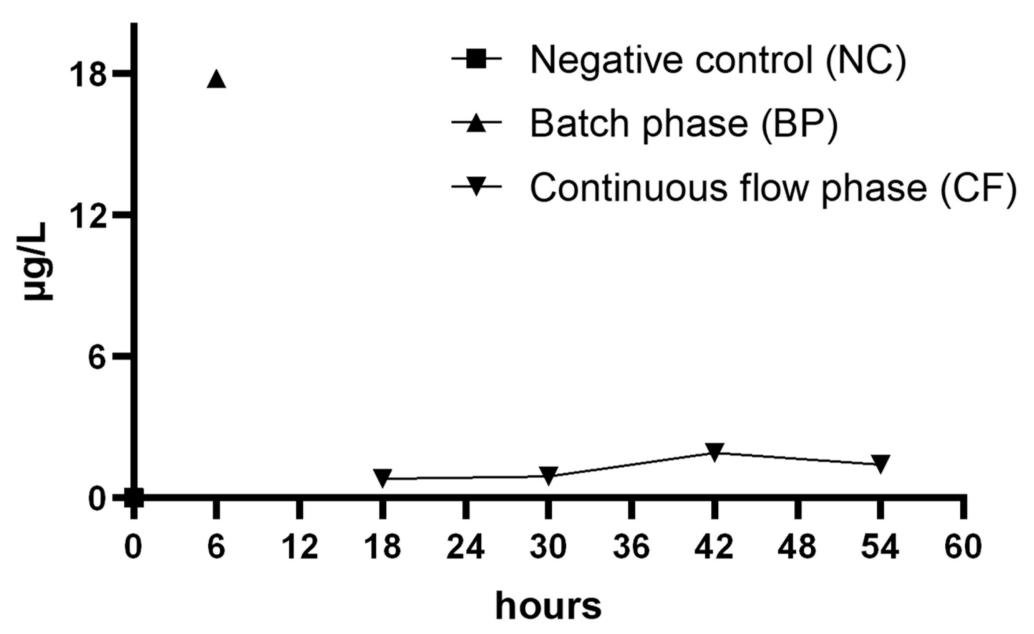

Figure 4. AgNPs release in the culturing medium during all phases of biofilm growth.

\subsection{Quorum Sensing Expression Analysis}

Results obtained by the relative expression analysis conducted by the Livak equation showed a 2.70-fold change of the $r h l R$ gene expression in cell growth in the presence of AgNPs (TiAl6V4-AgNPs vs. TiAl6V4) and a 0.33-fold change of the las $R$ gene.

\section{Discussion}

The results obtained in this study showed that AgNPs were released by the coated coupons and the remaining amount on the surface was unable to reduce microbial adhesion. In fact, no statistically significant difference was observed between coated and noncoated materials, regardless of their alloy. CoCr coupons demonstrated better properties for reducing the biofilm attachment.

Clinical studies showed the release of nanoparticles and ions due to the corrosion of orthopedic implants, causing significant production of inflammatory cytokines by tissues [22,23]. The toxicity of AgNPs was studied by AshaRani et al. on human lung fibroblast cells and human glioblastoma cells, demonstrating a cytotoxic, genotoxic, and antiproliferative rule of AgNPs at concentrations $>100 \mu \mathrm{g} / \mathrm{mL}$. [24].

The release of the silver coating is associated with the $\mathrm{pH}$ value of the medium, which modifies the surface charge and promotes the oxidative dissolution of the AgNPs, as well as the formation of aggregates by particles. The behavior of the particles varies in acid and alkaline conditions; the size of the particle aggregates decreases with increasing $\mathrm{pH}$, but it increases the stability, as reported by Fernando et al. [14]. The inhibitory effect of silver on microbial cells was evaluated; a study conducted by Yen-Chi Chen et al. [25] reported that $13.48 \mu \mathrm{g} / \mathrm{mL}(0.01348 \mu \mathrm{g} / \mathrm{L})$ was the minimum AgNP concentration needed to inhibit the growth of Escherichia coli. Gholamrezazadeh et al. [26] reported that $20.0 \pm 0.2 \mu \mathrm{g} / \mathrm{L}$ AgNPs Minimum Inhibitory Concentration (MIC) were capable of inhibiting P. aeruginosa growth. In our study, after $6 \mathrm{~h}$ of batch phase, the release of AgNPs was equal to $17.8 \pm 0.2 \mu \mathrm{g} / \mathrm{L}$, a concentration unable to prevent the planktonic cells attachment of $P$. aeruginosa on the surface. Regarding the effects of silver nanoparticles on the QS biofilm of P. aeruginosa, our results confirmed a study conducted by M. Gholamrezazadeh et al. [26], wherein they reported that AgNPs doubled the increase of the expression of the rhlR gene. Conversely, the lasR gene was more expressed in biofilm growth on the noncoated titanium coupons. In this stage of our study, gene expression analysis was performed only on biofilms grown on titanium coupons, but further research will need to be conducted to verify if this result is also obtained on cobalt-chromium coupons. In any case, the increased expression of the investigated genes is associated with the presence of silver and this could occur independently of the support material. 
Las is often considered the most important system in the P. aeruginosa QS regulation, since it is required to activate many genes including those coding for Rhl system. Recently, Kostylev M. et al. [27] report that the Rhl system can be activated in the absence of an active Las. This could explain the results obtained in our study, where a greater expression of the rhlR gene compared to the lasR gene was found. The RhIR Quorum Sensing receptor controls the P. aeruginosa expression of genes required for biofilm formation as well as genes encoding for virulence factors [28].

$\mathrm{CoCr}$ and titanium nanostructured prostheses are widely used for a combination of favorable properties, including mechanical strength, corrosion resistance and biocompatibility. Patel et al. [29] evaluated Staphylococcus aureus biofilm formation on $\mathrm{CoCr}$ and titanium alloy spinal implants in static condition, determining the optical density by spectrophotometer, and their results showed that titanium better prevented the biofilm formation then the CoCr alloy spinal implants. Castellanos et al. [30] evaluated Staphylococcus epidermidis biofilm formation on metal plates of titanium (Ti), porous titanium (p-Ti), cobalt-chromium (CoCr) and stainless steel (SS) in static condition. Their results showed a low adherence in $\mathrm{CoCr}$ without a significant difference compared to titanium plates. Our results, obtained with a different strain and in dynamic conditions, demonstrated that $\mathrm{CoCr}$ had a higher capacity to reduce the biofilm growth with a significant difference, as compared to titanium.

Regarding the resistance to mechanical stress, in clinical studies conducted by Smith et al. [31,32] reported an increasing rates of spinal rod fractures increased with the decreasing fatigue strength of the material employed, and an increase in fractures was found with titanium (Ti) rods compared to cobalt chromium ( $\mathrm{CoCr}$ ) rods after posterior spinal arthrodesis. Madl et al. [33] analyzed the toxicological implications of particles generated by the wear of metal-on-metal hip implants made of cobalt-chromium-molybdenum ( $\mathrm{CoCrMo}$ ) alloy, demonstrating a greater bio-persistence of $\mathrm{CoCr}$ particles and the induction of the inflammatory response. Although the results of animal studies showed that $\mathrm{CoCr}$ wear debris can disseminate into distant organs, there is still not enough evidence on the toxicity of these alloys [34]. Studies conducted by Baldwin et al. [35] highlighted that the inflammatory profile induced by $\mathrm{CoCr}$ remained consistent and elevated during the 28-day period with high cell counts associated with the implants and a progressive recruitment of $\mathrm{T}$ lymphocytes. Studies conducted by Walker [36] et al. in patients undergoing CoCr unicondylar knee arthroplasty, with a history of metal hypersensitivity, showed that the functional outcome and post-intervention survivorship were equivalent to those reported by patients without a history of metal hypersensitivity. In a systematic review conducted by Christian et al. [37] no evidence was found related to a causative relationship between $\mathrm{CoCr}$-containing hip implants and increased risk of systemic cancers. Further investigations are required to ensure safety in the use of this alloy.

In our study, the XRF and the LIBS analyses allowed us to qualitatively evaluate the coupons surface composition and to demonstrate the quality of production of these alloys. In this context, the CrCo analysis highlighted the pollution by copper and titanium probably due to manufacturing process errors.

Our study is one of the few in which biofilm adhesion was evaluated on implantable medical devices by a standard protocol, which provides for use of a dynamic model in continuous flow with optimal conditions mimicking a real scenario.

Our study had some limitations. It was not possible to compare the results obtained from similar studies that used the same materials and the dynamic study model of the biofilm. Therefore, it is desirable that this type of investigation be carried out in the future through the use of protocols that have verified reproducibility, such as the ASTM standard protocol.

Moreover, the bacterial strain recommended by the ASTM standard is not the most representative of strains associated with implantable device-related infections. Other strains, such as Staphylococcus epidermidis or fungal strains should be included and standardized in a new protocol.

Further studies need to be conducted in this field to achieve a deeper understanding of the concentration needed to increase the toxicity of AgNPs on biofilm-associated bacteria, without causing 
damage to host tissues and to understand how much this concentration is able to regulate the QS genes expression and then control the virulence of these strains.

\section{Conclusions}

The experimental model used allowed us to demonstrate that among the nanostructured materials, the $\mathrm{CoCr}$ alloy was the one with the greatest capacity to reduce microbial adhesion and biofilm formation.

The AgNPs nano-coating did not show influence on microbial adhesion, but the concentration used revealed the ability to induce the expression of one of the main QS systems, thus activating the virulence of the microbial strain studied.

The release of AgNPs in the culture medium highlighted the instability of the nano-coating.

In order to prevent implantable device-related infections, it is necessary to improve the ability of the nano-coating to inhibit microbial adhesion.

The inflammatory profile induced by $\mathrm{CoCr}$ and the formation of debris by alloy prostheses remain an interesting field of study to ensure safety in the use of these materials.

Author Contributions: S.L., B.C. (Beatrice Campanella), P.D.P., S.G., M.O., E.B., A.B., G.P.P., N.P., P.D.P. and B.C. (Beatrice Casini) conceived and designed the experiments. S.L., B.T., B.C. (Beatrice Campanella), S.G., M.O., E.B., M.T. and B.C. (Beatrice Casini), performed the experiments and wrote the paper and analyzed the data. All authors read and approved the manuscript.

Funding: This work was supported by the University of Pisa Research Project, PRA 2017/2018.

Acknowledgments: The authors wish to thank Dr Simone Leonetti for technical assistance during various stages of this investigation.

Conflicts of Interest: The authors declare no conflicts of interest.

\section{References}

1. Bozic, K.J.; Ries, M.D. The impact of infection after total hip arthroplasty on hospital and surgeon resource utilization. J. Bone Jt. Surg. Am. 2005, 87, 1746-1751.

2. Barberan, J. Management of infections of osteoarticular prosthesis. Clin. Microbiol. Infect. 2006, 12 (Suppl. 3), 93-101. [CrossRef] [PubMed]

3. Mattiassich, G.; Ortmaier, R.; Rittenschober, F.; Hochreiter, J. Diagnostic parameters in periprosthetic infections: The current state of the literature. Eur. J. Orthop. Surg. Traumatol. 2018, 28, 1573-1580. [CrossRef] [PubMed]

4. Kenney, C.; Dick, S.; Lea, J.; Liu, J.; Ebraheim, N.A. A systematic review of the causes of failure of Revision Total Hip Arthroplasty. J. Orthop. 2019, 16, 393-395. [CrossRef] [PubMed]

5. Deng, B.; Bruzzaniti, A.; Cheng, G.J. Enhancement of osteoblast activity on nanostructured $\mathrm{NiTi} /$ hydroxyapatite coatings on additive manufactured NiTi metal implants by nanosecond pulsed laser sintering. Int. J. Nanomed. 2018, 13, 8217-8230. [CrossRef] [PubMed]

6. Nasiri, N.; Mukherjee, S.; Panneerselvan, A.; Nisbet, D.R.; Tricoli, A. Optimally Hierarchical Nanostructured Hydroxyapatite Coatings for Superior Prosthesis Biointegration. ACS Appl. Mater. Interfaces 2018, 10, 24840-24849. [CrossRef]

7. Huang, Y.; Song, G.; Chang, X.; Wang, Z.; Zhang, X.; Han, S.; Su, Z.; Yang, H.; Yang, D.; Zhang, X. Nanostructured Ag+-substituted fluorhydroxyapatite- $\mathrm{TiO}_{2}$ coatings for enhanced bactericidal effects and osteoinductivity of Ti for biomedical applications. Int. J. Nanomed. 2018, 13, 2665-2684. [CrossRef]

8. Liu, L.; Bhatia, R.; Webster, T.J. Atomic layer deposition of nano- $\mathrm{TiO}_{2}$ thin films with enhanced biocompatibility and antimicrobial activity for orthopedic implants. Int. J. Nanomed. 2017, 12, 8711-8723. [CrossRef]

9. Zhou, Y.; Kheir, M.; Antoci, V.; Zagra, L. Can a Biomaterial Surface Be Modified to Dispel Bacterial Adherence and Biofilms? What Are the Potential Concerns in Modifying Implant Surfaces to Combat Biofilms? Final ICM Document; ICM Philly: Philadelphia, PA, USA, 2018.

10. Ilea, A.; Vrabie, O.G.; Băbțan, A.M.; Miclăuş, V.; Ruxanda, F.; Sárközi, M.; Barbu-Tudoran, L.; Mager, V.; Berce, C.; Boșca, B.A.; et al. Osseointegration of titanium scaffolds manufactured by selective laser melting in rabbit femur defect model. J. Mater. Sci. Mater. Med. 2019, 30, 26. [CrossRef] 
11. Shah, F.A.; Omar, O.; Suska, F.; Snis, A.; Matic, A.; Emanuelsson, L.; Norlindh, B.; Lausmaa, J.; Thomsen, P.; Palmquist, A. Long-term osseointegration of 3D printed CoCr constructs with an interconnected open-pore architecture prepared by electron beam melting. Acta Biomater. 2016, 36, 296-309. [CrossRef]

12. Liao, C.; Li, Y.; Tjong, S. Bactericidal and Cytotoxic Properties of Silver Nanoparticles. Int. J. Mol. Sci. 2019, 20, 449. [CrossRef] [PubMed]

13. Lee, S.H.; Jun, B.H. Silver Nanoparticles: Synthesis and Application for Nanomedicine. Int. J. Mol. Sci. 2019, 20, 865. [CrossRef] [PubMed]

14. Fernando, I.; Zhou, Y. Impact of $\mathrm{pH}$ on the stability, dissolution and aggregation kinetics of silver nanoparticles. Chemosphere 2019, 216, 297-305. [CrossRef] [PubMed]

15. Magana, M.; Sereti, C.; Ioannidis, A.; Mitchell, C.A.; Ball, A.R.; Magiorkinis, E.; Chatzipanagiotou, S.; Hamblin, M.R.; Hadjifrangiskou, M.; Tegos, G.P. Options and limitations in clinical investigation of bacterial biofilms. Clin. Microbiol. Rev. 2018, 31, e00084-16. [CrossRef]

16. Merritt, J.H.; Kadouri, D.E.; O'Toole, G.A. Growing and analyzing static biofilms. Curr. Protoc. Microbiol. 2005, 22, 1B.1.1-1B.1.18.

17. Van Kerckhoven, M.; Hotterbeekx, A.; Lanckacker, E.; Moons, P.; Lammens, C.; Kerstens, M.; Ieven, M.; Delputte, P.; Jorens, P.G.; Malhotra-Kumar, S.; et al. Characterizing the in vitro biofilm phenotype of Staphylococcus epidermidis isolates from central venous catheters. J. Microbiol. Methods 2016, 127, 95-101. [CrossRef]

18. ASTM E2647-13. Standard Test Method for Quantification of Pseudomonas Aeruginosa Biofilm Grown Using Drip Flow Biofilm Reactor with Low Shear and Continuous Flow; ASTM International: West Conshohocken, PA, USA, 2013; Available online: https://www.astm.org/ (accessed on 20 January 2020).

19. Bratu, S.; Gupta, J.; Quale, J. Expression of the las and rhl quorum-sensing systems in clinical isolates of Pseudomonas aeruginosa does not correlate with efflux pump expression or antimicrobial resistance. J. Antimicrob. Chemother. 2006, 58, 1250-1253. [CrossRef]

20. Livak, K.J.; Schmittgen, T.D. Analysis of Relative Gene Expression Data Using Real-Time Quantitative PCR and the 2- $\Delta \Delta \mathrm{CT}$ Method. Methods 2001, 25, 402-408. [CrossRef]

21. Legnaioli, S.; Lorenzetti, G.; Pardini, L.; Cavalcanti, G.H.; Palleschi, V. Double and multiple pulse LIBS techniques. In Springer Series in Optical Sciences; Springer: Berlin/Heidelberg, Germany, 2014; Volume 182, pp. 117-141.

22. Gibon, E.; Amanatullah, D.F.; Loi, F.; Pajarinen, J.; Nabeshima, A.; Yao, Z.; Hamadouche, M.; Goodman, S.B. The Biological Response to Orthopaedic Implants for Joint Replacement. J. Biomed. Mater. Res. B Appl. Biomater. 2017, 105, 2162-2173. [CrossRef]

23. Papageorgiou, I.; Abberton, T.; Fuller, M.; Tipper, J.L.; Fisher, J.; Ingham, E. Biological Effects of Clinically Relevant CoCr Nanoparticles in the Dura Mater: An Organ Culture Study. Nanomaterials 2014, 4, 485-504. [CrossRef]

24. AshaRani, P.V.; Low Kah Mun, G.; Hande, M.P.; Valiyaveettil, S. Cytotoxicity and Genotoxicity of Silver Nanoparticles in Human Cells. ACS Nano 2008, 3, 279-290. [CrossRef] [PubMed]

25. Chen, Y.-C.; Yu, K.-P. Enhanced antimicrobial efficacy of thermal-reduced silver nanoparticles supported by titanium dioxide. Colloids Surf. B Biointerfaces 2017, 154, 195-202. [CrossRef] [PubMed]

26. Gholamrezazadeh, M.; Shakibaie, M.R.; Monirzadeh, F.; Masoumi, S.; Hashemizadeh, Z. Effect of nano-silver, nano-copper, deconex and benzalkonium chloride on biofilm formation and expression of transcription regulatory quorum sensing gene (rh1R) in drug-resistance Pseudomonas aeruginosa burn isolates. Burns 2018, 44, 700-708. [CrossRef] [PubMed]

27. Kostylev, M.; Kim, D.Y.; Smalley, N.E.; Salukhe, I.; Greenberg, E.P.; Dandekar, A.A. Evolution of the Pseudomonas aeruginosa quorum-sensing hierarchy. Proc. Natl. Acad. Sci. USA 2019, 116, 7027-7032. [CrossRef]

28. Mukherjee, S.; Moustafa, D.; Smith, C.D.; Goldberg, J.B.; Bassler, B.L. The RhlR quorumsensing receptor controls Pseudomonas aeruginosa pathogenesis and biofilm development independently of its canonical homoserine lactone autoinducer. PLoS Pathog. 2017, 13, e1006504. [CrossRef]

29. Patel, S.S.; Aruni, W.; Inceoglu, S.; Akpolat, Y.T.; Botimer, G.D.; Cheng, W.K.; Danisa, O.A. comparison of Staphylococcus aureus biofilm formation on cobalt-chrome and titanium-alloy spinal implants. J. Clin. Neurosci. 2016, 31, 219-223. [CrossRef] 
30. Castellanos, J.; González-Cuevas, A.; Sierra, J.M.; García-Nuño, L.; Diaz-Brito, V.; Soriano, A.; Font-Vizcarra, L. Adherence of S. epidermidis on different metals. A comparative in vitro study. J. Appl. Biomater. Funct. Mater. 2014, 12, 141-144. [CrossRef]

31. Smith, J.S.; Shaffrey, E.; Klineberg, E.; Shaffrey, C.I.; Lafage, V.; Schwab, F.J.; Protopsaltis, T.; Scheer, J.K.; Mundis, G.M., Jr.; Fu, K.-M.G.; et al. Prospective multicenter assessment of risk factors for rod fracture following surgery for adult spinal deformity. J. Neurosurg. Spine 2014, 1-10. [CrossRef]

32. Smith, J.S.; Shaffrey, C.I.; Ames, C.P.; Demakakos, J.; Fu, K.-M.G.; Keshavarzi, S.; Li, C.M.Y.; Deviren, V.; Schwab, F.J.; Lafage, V.; et al. Assessment of symptomatic rod fracture after posterior instrumented fusion for adult spinal deformity. Neurosurgery 2012, 71, 862-867. [CrossRef]

33. Madl, A.K.; Kovochich, M.; Liong, M.; Finley, L.B.; Paunstenbach, D.J.; Oberdörster, G. Toxicology of wear particles of cobalt-chromium alloy metal-on-metal hip implants Part II: Importance of physicochemical properties and dose in animal and in vitro studies as a basis for risk assessment. Nanomed. Nanotechnol. Biol. Med. 2015, 11, 1285-1298. [CrossRef]

34. Brown, C.; Lacharme-Lora, L.; Mukonoweshuro, B.; Sood, A.; Newson, R.B.; Fisher, J.; Case, C.P.; Ingham, E. Consequences of exposure to peri-articular injections of micro- and nano-particulate cobalt-chromium alloy. Biomaterials 2013, 34, 8564-8580. [CrossRef]

35. Baldwin, L.; Hunt, J.A. Host inflammatory response to $\mathrm{NiCr}, \mathrm{CoCr}$, and $\mathrm{Ti}$ in a soft tissue implantation model. J. Biomed. Mater. Res. Part A 2006, 79, 574-581. [CrossRef]

36. Walker, T.; Rutkowski, L.; Innmann, M.; Panzram, B.; Herre, J.; Gotterbarm, T.; Aldinger, P.R.; Merle, C. Unicondylar knee arthroplasty using cobalt-chromium implants in patients with self-reported cutaneous metal hypersensitivity. Bone Jt. J. 2019, 101, 227-232. [CrossRef]

37. Christian, W.V.; Oliver, L.D.; Paustenbach, D.J.; Kreider, M.L.; Finley, B.L. Toxicology-based cancer causation analysis of $\mathrm{CoCr}$-containing hip implants: A quantitative assessment of genotoxicity and tumorigenicity studies. J. Appl. Toxicol. 2014, 34, 939-967. [CrossRef]

(C) 2020 by the authors. Licensee MDPI, Basel, Switzerland. This article is an open access article distributed under the terms and conditions of the Creative Commons Attribution (CC BY) license (http://creativecommons.org/licenses/by/4.0/). 